\title{
Radicalmente universal y diferencialista. Por una geografía crítica desde América Latina
}

\section{Radically universal and differentialist. For a critical geography from Latin America}

\author{
Tania Herrera
}

Pontificia Universidad Católica del Perú.

t.herrera@pucp.pe

\begin{abstract}
RESUMEN
En este ensayo se reflexiona acerca de lo que implica para la geografía y las ciencias sociales el análisis crítico de la realidad. Ello requiere no perder de vista la universalidad del capitalismo y de los intereses multiescalares que producen espacio. Asimismo, ello requiere dar cabida a la subjetividad y a todo lo que rebasa al concepto de clase. Esta reflexión ha de iluminar la sombra que deja una perniciosa actitud de investigadores que se identifican con teoría postcolonial y pretenden comprender los territorios latinoamericanos bajo referentes conceptuales nativos, un arreglo de palabras creado localmente. $\mathrm{Si}$ algo cabe rescatar de estas ideas, eso es la denuncia implícita a los poderes que dictan las normas de producción y circulación de conocimiento, íntimamente ligados a intereses geopolíticos globales. Así, se propone un recorrido por la génesis de la geografía crítica, antimperialista y militante desde su inicio. Enseguida, se propone un diálogo entre dos grandes autores del siglo XX, Henri Lefebvre y José María Arguedas; de Lefebvre se desarrolla el concepto de diferencia y se ejemplifica dicho concepto a través de una historia presente en "Los Ríos Profundos". Este diálogo busca provocar reacciones a quienes insisten en que no se puede comprender Latinoamérica y sus territorios con categorías creadas en espacios fuera de los límites continentales.
\end{abstract}

Palabras clave: Geografía crítica; materialismo; diferencialismo.

\begin{abstract}
This essay proposes an insight on what implies the critical analysis of reality for geography and social sciences. Such critical view requires considering the universality of capitalism and the multiscale interests that produce space. Likewise, it is important to consider subjectivity and everything that goes beyond the concept of class. In this sense, it is necessary to point out the shadow left by a pernicious attitude of researchers identified with postcolonial theory, who seek to understand the Latin American territories under local conceptual referents, an arrange of words locally created. If something can be rescued from these ideas, that is the implicit denunciation to the powers that dictate the norms of production and circulation of knowledge, intimately linked to global geopolitical interests. Thus, the essay proposes a journey through the genesis of critical, anti-imperialist and militant geography. Next, a dialogue is proposed between two great authors of the 20th century, Henri Lefebvre and José María Arguedas; of Lefebvre we take the concept of difference and exemplify this concept through a story written by Arguedas in "Los Ríos Profundos". The objective with this dialogue is to provoke reactions to those who insist that Latin America and its territories cannot be understood through categories created outside the continental limits.
\end{abstract}

Keywords: Critical geography; materialism; differentialism.

\section{Citar como:}

Herrera, T. (2019). Radicalmente universal y diferencialista. Por una geografía crítica desde América Latina. Espiral, revista de geografías y ciencias sociales, 1(1), 045 - 058. http://dx.doi.org/10.15381/espiral.v1i1.15845 
El objetivo de este ensayo es discutir qué implica el pensamiento crítico universal en el quehacer geográfico. Si consideramos la diferencia y especificidad de las demandas espaciales de diferentes grupos sociales, la geografía crítica -y con ella el análisis espacial- tiene a su disposición diversos métodos que permiten comprender y tender puentes entre lo que sucede en distintos lugares del mundo; por ello, se dice que el análisis geográfico crítico es, en esencia, multiescalar. La reflexión que se propone surge de una seria preocupación, frente a una actitud empecinada de algunos investigadores que buscan comprender los territorios latinoamericanos, exclusivamente, bajo referentes conceptuales producidos localmente. El recelo por emplear métodos o marcos conceptuales producidos en países de capitalismo avanzado ${ }^{1}$ se justificaría por la poca utilidad que tendrían para ayudarnos a comprender lo que pasa en nuestras localidades, como si el capitalismo global fuese tan abstracto, incapaz de materializarse en los territorios ${ }^{2}$. Tal idea parece completamente perniciosa debido a que, en vez de abrir el horizonte conceptual para enriquecer el análisis, lo cierra y limita de antemano.

No sin razón, se ha señalado que los latinoamericanos vivimos una particular subjetividad impregnada de dualismo, resultado de una específica manera de experimentar la relación entre historia y tiempo, a la vez secuencia y simultaneidad (Quijano, 1988). Cabe preguntarse si este dualismo es exclusivo de las sociedades latinoamericanas y si, dado el proceso de globalización capitalista imperante, esta subjetividad no habría contaminado y a la vez se habría contaminado de otras, volcándose necesariamente hacia una hibridación.

La teoría postcolonial ha recibido duras críticas de autores identificados con la Teoría Crítica, entre ellos Vivek Chibber, quien cuestiona los argumentos psicologizantes que apelan a una específica subjetividad. Tales argumentos rechazarían los esfuerzos por comprender procesos sociales en sociedades colonizadas con los mismos referentes teóricos con los que se podría buscar comprender procesos sociales en otras partes del mundo. Para la teoría postcolonial, emplear un mismo marco teórico no sería posible, entre otras razones, porque en las sociedades que fueron colonizadas la motivación principal de las acciones individuales y colectivas no responde a un cálculo utilitario, o a cierto racionalismo que busque satisfacer intereses materiales. Antes bien, habría que entenderlas en sus propias formas constitutivas, lo que haría necesaria la emergencia de categorías nativas (Chibber, 2013: 18). El recurso a la subjetividad es común en las posturas académicas postcoloniales y parece que, antes que abrir la posibilidad de comprender un hecho en sus manifestaciones multiescalares, cierra filas a los intentos de comparación internacionales norte-sur ${ }^{3}$ y adjetiva tales esfuerzos de eurocéntricos o colonialistas.

\footnotetext{
1 Los países de capitalismo avanzado son aquellos que conocieron temprana e intensamente procesos de industrialización y que, desde hace unas décadas, enfrentan procesos de reestructuración económica, volcada hacia la acumulación flexible. 2 A propósito, véase el texto publicado por Eduardo Gudynas (2015), donde discute la moda que supondría, para los intelectuales latinoamericanos, citar los textos del geógrafo David Harvey y acogerse a un bagaje conceptual producido en el norte. En el texto, Gudynas habla del capitalismo global como algo que sería muy abstracto y distinto a lo que podríamos entender como un contemporáneo capitalismo local o interno, que tendría matices propios en América Latina. Respecto a las insuficiencias de la "moda Harvey", dice: "Insisto en que muchas de sus tesis son compartibles al ofrecer un valioso instrumental para entender el capitalismo global. Pero la cuestión clave que se debe considerar es si esos aportes son suficientes para entender lo que sucede en América Latina, en nuestro continente, y en este preciso momento, a inicios del siglo XXI."

3 La referencia "norte-sur" se basa en la idea simplificada de que todo el mundo se divide en dos hemisferios. En el hemisferio norte estarían los países de capitalismo avanzado que conocieron tempranamente un proceso de industrialización y que habrían impulsado procesos de imperialismo cultural, económico y político. En el hemisferio sur, en cambio, estarían los países más pobres del mundo (el Tercer mundo) que más bien habrían vivido procesos de colonización que determinaron su rumbo económico-político, centrado en el abastecimiento de materias primas para los países del norte. Los desarrollos desiguales vividos por los países de cada continente permiten matizar tal generalización.
}

046 | Espiral 1(1): 046 - 058 
Chibber sostiene que este argumento estriba en una concepción diferenciada de la historia del capitalismo en cada una de las dos zonas (norte y sur) y, de esta manera, pone en entredicho la universalización del capitalismo. "En el corazón del proyecto subalterno, y más generalmente en el de la teoría postcolonial, se erige la tesis de que hay una profunda brecha separando a las naciones capitalistas occidentales del mundo postcolonial" (2013: 50-51). Así, uno de los argumentos centrales de las posturas postcoloniales es que, mientras Occidente ${ }^{4}$ refleja una estable integración de la cultura política (lo que denotaría el consentimiento del pueblo), el Oriente continúa en una situación de fuerzas difusas e inestables. Por último, las teorías postcoloniales sostienen que las "teorías abstractas" son incapaces de aprehender la producción y persistencia de las diferencias sociales, como si las categorías universales presupusieran un paisaje social plano, libre de rugosidades. "Lo universal es igualado con lo homogéneo", advierte Chibber (2013: 150), al tiempo que resalta cómo se subestima la capacidad del capitalismo para adaptarse a la heterogeneidad y cómo, con la celebración de lo local -de lo particular-, se justifica la exotización de las sociedades por medio de una lectura metafísica.

En la producción académica latinoamericana de geografía y ciencias sociales se observa una vital ebullición de enfoques contestatarios del status quo, varios de ellos centrados en la defensa de la diversidad cultural desde posturas postcoloniales, antiextractivistas y feministas ${ }^{5}$. Sin embargo, la gran pregunta que anima estas reflexiones busca dar unos pincelazos respecto a cómo incluir, en el análisis espacial llevado a cabo por geógrafos y otros investigadores, las diferencias materiales y subjetivas de la realidad local. No nos sirve un marco conceptual que, pretendiéndose crítico y progresista, rechace la hibridación de teorías globales (sean estas producidas en el norte o en el sur) y trabajos empíricos locales. Asimismo, poco o nada ayuda refugiarse en un localismo metafísico solipsista que rechace las condiciones económicopolíticas estructurantes del modo de funcionamiento de la sociedad capitalista en la que vivimos. En otras palabras, se defiende que las diferencias culturales y económicas deben ser reconocidas sin caer en relativismos culturales ni en posturas postmaterialistas. Escapar de la metafísica requiere afirmarse en la economía política y dar el giro cultural sin dejar de lado la estructuración de las condiciones materiales de vida.

Para responder a la pregunta planteada, seconsidera necesario familiarizar al lector con la historia de la geografía crítica, resaltando cuáles son sus principales características e instituciones. El recuento de esta historia es limitado y no busca desmerecer los esfuerzos latinoamericanos, ni a los individuos con pensamiento crítico que han hecho Geografía fuera de los estándares imperialistas y extractivistas imperantes en América Latina, pero reconoce dónde emergen -espaciotemporalmente- los referentes institucionales de la geografía crítica. Asimismo, la evocación de esta historia insiste en la pluralidad y apertura de la geografía crítica para contaminarse con enfoques actuales. En la segunda parte, se indaga qué implica abrazar los aspectos culturales específicos sin dejar de lado el análisis materialista multiescalar. Se ha advertido que el despertar postmoderno desplazó al concepto de clase y que tal cambio ha influido en la producción de conocimiento desde la Geografía ${ }^{6}$. El interés de este ensayo es defender la necesaria inclusión de múltiples enfoques para el análisis espacial, sin perder de vista el rol central que juegan los intereses de clase en la producción del espacio. Para una comprensión didáctica, se discute el concepto de diferencia, tal como ha sido desarrollado por Henri Lefebvre (1970), tomando como punto de apoyo un capítulo de Los Ríos Profundos, escrito por José María Arguedas y publicado en 1958.

4 Se emplea la diferenciación Occidente-Oriente haciendo eco a la dicotomía norte-sur; es decir, para generalizar a aquellos países que lideraron el imperialismo cultural y la hegemonía económico-política. La diferencia del término OccidenteOriente, tal vez, radica en el énfasis dado a los procesos culturales.

5 Un ejemplo de ello es el reciente libro de Rocío Silva-Santisteban (2017), donde la autora combina un interesante enfoque feminista y otro post-extractivista.

6 A propósito, ver Albet y otros (2004). 
El puente entre la historia que narra este capítulo y el concepto de diferencia se hará desde la geografía crítica, en clave de género y de clase.

\section{El origen angloamericano y antimperialista de la geografía crítica}

La revisión bibliográfica sobre la historia de la geografía crítica señala su origen angloamericano; la geografía crítica surge en Estados Unidos entre los años 1960 y 1970. Se trata de un movimiento espontáneo de raíces teóricas marxistas, anarquistas y socialistas, cuyo propósito es contestar la práctica geográfica íntimamente vinculada a la acción militar e imperialista (Berg, 2010). Con un discurso anticolonial y en defensa de las luchas anticapitalistas, jóvenes geógrafos de diversas orientaciones políticas se reúnen bajo la expresión "geografía radical" y encuentran, en la entonces emergente revista Antipode: A journal of radical geography, el espacio propicio desde el cual difundir sus investigaciones (Gintrac, 2012; Gómez et al, 1988). Antipode surge en $1969^{7}$ por iniciativa de Jim Blaut, David Stea y algunos estudiantes de postgrado de la Clark University, quienes sienten profunda necesidad de que la Geografía tome posición respecto a problemas sociales de la época, como la movilización a favor de los derechos civiles y los movimientos pacifistas contra la guerra de Estados Unidos en Vietnam (Benach, 2012). Lo diferente fue contestar las variadas formas de opresión y tomar posición por los grupos oprimidos.

Josefina Gómez y sus coautores (1988) identificaron tres grandes fases del pensamiento geográfico: el decimonónico (siglo XIX), el clásico (siglo XX) y las tendencias actuales, consideradas a partir de1960. Dentro deesta última fase seencuentran tres perspectivas: las analíticas y sistémicas del conocimiento geográfico, las fenomenológicas y sistémicas en el análisis geográfico de la percepción y del comportamiento espacial, y los radicalismos geográficos. Aunque suelen considerarse como una misma corriente, la geografía radical anida en la geografía crítica que, como veremos enseguida, se define por su carácter plural, militante e internacional.

\section{a) Pluralización de las vías y corrientes explicativas}

Como señala Cécile Gintrac, antes que evocar posturas ortodoxas, el término radical implica buscar comprender las causas de los problemas, sus raíces. El rechazo a la predominante corriente analítica en la geografía constituyó un elemento común en la identidad de la geografía radical. Si bien desde 1973 la geografía radical se empleó como sinónimo de geografía marxista, en un libro sobre la obra de Richard Peet, Núria Bénach señala que esta nueva geografía recuperó algunas obras clásicas, como la teoría de los lugares centrales de W. Christaller, la teoría de la localización industrial de A. Weber, y la "teoría de la localización y el modelo de usos del suelo agrícola", de J.H. Von Thunen (Bénach, 2012: 20). Lo distintivo de la geografía radical fue su meticulosa atención a la materialización de los procesos sociales en el espacio, con importantes avances teóricos en la comprensión del capitalismo.

Desde fines de 1980, la geografía radical, esencialmente trabajada por geógrafos británicos y norteamericanos, se inscribe en el seno de la geografía crítica, más general, donde la noción de clase pierde centralidad explicativa y es rebasada (Gintrac, 2012; Cox, 2005; Berg, 2010). Ello no quita, naturalmente, la existencia de geógrafos que se reivindican exclusivamente de una tradición radical (marxista o anarquista). Dos eventos fueron decisivos: la comercialización de la revista Antipode, en 1986, y el desplazamiento de la categoría clase en el análisis geográfico, en beneficio de

$7 \quad$ Richard Peet estuvo en la dirección de esta revista entre 1970 y 1985 y, como señala Núria Benach, "(...) se convirtió en un animador incansable de la geografía radical, luego explícitamente de la geografía marxista, a través de su dedicación a la revista Antipode, al tiempo que continuaba y diversificaba sus líneas propias de trabajo" (Benach, 2012: 24).

048 | Espiral 1(1): 048 - 058 
la inclusión de voces feministas, ambientalistas, antirracistas y otras (Bénach, 2012). Así, los movimientos sociales de la década de 1960 cobran fuerza y ponen otros temas en la agenda de investigación geográfica. Este proceso es recogido por el término giro cultural y debe ser comprendido al tiempo que se analizan los cambios en la economía política, específicamente, el paso de un modo de producción fordista a otro de acumulación flexible.

Antes que un campo coherente de conocimiento, debe entenderse a la geografía crítica desde una apuesta pedagógica emancipadora. Como señala Cécile Gintrac (2012), la geografía crítica acopla, bajo influencia de teorías postmodernas, la deconstrucción de discursos dominantes. Así, la geografía crítica es receptiva a diferentes perspectivas: anarquismo, anti-racismo, medioambientalismo, feminismo, marxismo, postmarxismo, post-colonialidad, post-estructuralismo, estudios queer, psicoanálisis, situacionismo, socialismo (Berg, 2010). Se trata de una pluralización de las vías, de una apertura antes que de un encogimiento.

\section{b) Compromiso militante}

Se ha dicho que la geografía crítica no es un campo de conocimiento, sino una práctica, un interés emancipador (Koninck, 2004 en Gintrac, 2012). Gómez y sus coautores definen al movimiento radical en la geografía como "(...) un movimiento intencional y profundamente crítico que se fija como tarea prioritaria la denuncia del conservadurismo e ideologismo científicos y la responsabilidad de reasumir el compromiso geográfico con la práctica de la persecución de la justicia social" (Gómez et al, 1988: 143). La geografía crítica es impensable sin su relación a la acción, la cual se realizaría, por ejemplo, a través del compromiso de los investigadores con movimientos sociales progresistas que apuestan por la justicia social.

En la Enciclopedia de Geografía, aparecida en 2010, el geógrafo canadiense Lawrence Berg caracteriza lo que sería la Geografía Crítica Humana, término que aparece en 1990 en la geografía anglófona y que representa una coalición, un conjunto diverso de ideas y prácticas que tienen en común el compromiso con políticas emancipadoras y un campo social-progresista. Como lo recuerda Berg, los geógrafos críticos están comprometidos con la transformación de sus mundos y llaman a reflexionar sobre cómo debemos interpretar las relaciones espaciales existentes a fin de mejorarlas. Asimismo, siguiendo a Berg, los geógrafos críticos reconocen en el activismo y en la participación política los campos donde conseguir sus objetivos (Berg, 2010: 617).

Pero, ¿qué implica el compromiso militante en el quehacer académico de los geógrafos? Es insostenible defender el dualismo bajo el cual suele quedar subsumida la relación entre acción y conocimiento, pues tal dicotomía implica que no existe trabajo intelectual en los espacios estrechamente vinculados a la acción directa (por ejemplo, en colectivos en defensa de derechos laborales), y que de poco o nada sirve, en términos prácticos, el trabajo de investigación hecho en el seno de universidades $\mathrm{u}$ otras instituciones. Parafraseando a Don Mitchell (2008), hay que considerar que la praxis revolucionaria no puede realizarse desde un solo frente, requiere nuestra inserción en diferentes campos, todos ellos mutuamente necesarios.

\section{c) Búsqueda de internacionalización}

A diferencia de la geografía radical, que según Cécile Gintrac no tuvo intención de congregar a geógrafos fuera de los círculos de geógrafos anglófonos, la geografía crítica sí se preocupó por afirmar una dimensión internacional (Gintrac, 2012). La tendencia a tejer redes internacionales acompañó a la geografía crítica desde su inicio. El término geografía crítica se empieza a utilizar por los geógrafos en 1980, con la realización del Nordic Symposium on Critical Geography. El término vuelve a sonar dos años más tarde con la publicación de una serie de libros de la editorial 
Macmillan Publishers bajo el título "Critical Human Geography" (Berg, 2010: 620). Con estos antecedentes, puede situarse la institucionalización de la geografía crítica en 1995, cuando un grupo de geógrafos ingleses crea la plataforma virtual "The Critical Geography Forum", que servirá como espacio donde discutir temas diversos y organizar reuniones. En 1997, se realiza en Vancouver la "International Conference of Critical Geographers (ICCG)", donde se crea el International Critical Geography Group (Berg, 2010: 621). Pese a originarse en Estados Unidos e Inglaterra (Gómez et al, 1988), la geografía crítica goza actualmente de un interés creciente entre investigadores y estudiantes de diversas partes del mundo, quienes han contribuido a diversificar las líneas de investigación y los referentes.

Gintrac aclara que el término "geografía crítica" nunca fue importado a Francia, donde existían otras corrientes predominantes. Ella señala que el término "crítico" aparece en Francia en 1975, por primera vez, con la revista "Espaces-Temps. Revue francaise de géographie critique". El mismo año, en España, algunos geógrafos liderados por Horacio Capel fundan Geocrítica (Gintrac, 2012). Como señala Gintrac, lo crítico es entendido como necesidad de romper con las teorías geográficas dominantes y renovar la disciplina. En diversas partes del mundo, se sentía la necesidad de romper con una tradición de hacer geografía que negaba la posibilidad de un cambio radical de la sociedad, servil a intereses hegemónicos imperialistas, de espaldas a las injusticias sociales.

Gómez y sus coautores sostienen que una de las diferencias entre la academia francesa y la norteamericana o inglesa era "(...) la mayor permeabilidad política de las universidades francesas, y una presencia del pensamiento marxista más o menos tibia o profunda, pero, al menos en parte, asumida académicamente" (1988: 139). Mencionan también que el espíritu de mayo del 68 contribuyó a una toma de posturas contestatarias. Yves Lacoste articularía las voces radicales en Francia alrededor de la revista Herodote, fundada en 1977, cuyo programa buscaba “(...) clarificar los contenidos ideológicos y estratégicos del saber geográfico en sus relaciones con el poder -o los poderes-, denunciar la obra de mistificación de gran amplitud del saber académico" (Gómez et al, 1988:139).

El papel de Herodote en Francia fue comparable al que jugó Antipode en Estados Unidos (Benach, 2012). Lacoste criticó los enfoques regionales de origen vidaliano (nivel predilecto en la geografía tradicional), pues habrían "(...) impedido la consideración de otras representaciones espaciales", además de haber "(...) imposibilitado la comprensión de la «espacialidad diferencial», de los muy diversos comportamientos y escalas de las prácticas espaciales" [citado en Gómez et al, 1988: 145-146]. La geografía regional fue muy influyente en España y en América Latina. Se esperaba que el geógrafo, desde un abordaje analítico de los componentes físico y humano, llegue a una síntesis que englobe los principales aspectos de la comarca, su personalidad (Vilà Valentí, 1986).

Según los elementos presentados, podemos definir la geografía crítica como una apuesta intelectual progresista que surge para contestar posturas conservadoras e imperialistas. La geografía crítica implica una apertura respecto a categorías de análisis que van más allá de la clase y las estructuras económicas; en este sentido, desde el reconocimiento de las múltiples caras de la opresión ${ }^{8}$, se sirve necesariamente de diferentes marcos conceptuales para analizar las manifestaciones espaciales de los conflictos sociales, abraza a la geografía radical y la enriquece. También, afirma una dimensión internacional que reconoce las diferentes escalas comprendidas en la producción del espacio y del conocimiento. Es gracias a esta apertura que la geografía crítica permite tender puentes muy fructíferos entre el conocimiento espacial, trabajado desde la geografía, y la teoría social de manera más amplia. La apuesta por

8 Iris Marion Young (2000) propone entender la opresión en sus distintas manifestaciones o caras, entre las que cuentan la violencia, la explotación y el imperialismo cultural. La referencia a su obra es relevante porque la articulación entre geografía y filosofía política es aún una tarea pendiente que debemos emprender con entusiasmo.

050 | Espiral 1(1): 050 - 058 
lo universal requiere pensar el poder en sus reconfiguraciones multiescalares, en las interdependencias existentes entre un nivel global y otro local.

\section{Radicalidad universal y diferencialista. Los aportes de Henri Lefebvre y José María Arguedas}

Pese al interés que muestran las ciencias sociales desde hace unas décadas por la dimensión espacial, el giro espacial implica dos grandes ironías. Una de ellas tiene que ver con la persistencia de metáforas espaciales que subyacen en conceptos de transparencia espacial. La transparencia implica pensar el espacio como un contenedor vacío y no como un conjunto dinámico de relaciones en movimiento, donde la interacción entre sociedades, y entre sociedades y medio físico, no cesa. La segunda ironía tiene que ver con la invisibilización de ciertas geografías, en un contexto donde las universidades anglo-americanas dictan la norma y los límites que definen hasta dónde y por qué caminos debe pasear la investigación geográfica9 . Por ello, Berg (2004) propone que entendamos el proceso de escalamiento del conocimiento como parte de relaciones socio-espaciales hegemónicas en la geografía, en un contexto donde la acumulación académica configura sus propias estrategias. Las relaciones de poder en la academia no sólo consideran el origen geográfico de la teoría, sino también el alineamiento con principios neoliberales hoy dominantes (competencia, productividad, privatización). Frente a esto, la geografía crítica implicaría resistir, crear otras formas de hacer y difundir el conocimiento espacial.

No se puede entender la producción de conocimiento espacializado en América Latina sin la importante influencia que tuvieron las escuelas anglosajonas y francesas. Como dicen Pedro Urquijo y Gerardo Bocco, "(e)s complicado hablar de una geografía latinoamericana que pueda contraponerse a las tradiciones de la geografía europea o del norte de América" (2016: 158), y ellos dan algunas razones. (1) La Geografía latinoamericana se nutre tanto de la Geografía europea como de la norteamericana. (2) La conformación histórica de la disciplina en América Latina recurre a clásicos europeos y norteamericanos para su base epistemológica. (3) Es complicado afirmar que exista un pensamiento totalmente latinoamericano sin recurrir a los autores europeos y norteamericanos. Se trataría, más bien, de apoyarse en las diferentes tradiciones para desarrollar un pensamiento al mismo tiempo situado y universal.

Apostar por la universalidad en el conocimiento requiere repensar la tensión homogéneo-diferente, mirar más allá de los límites continentales para buscar ángulos con los cuales estirar el pensamiento a nuevos puertos. El pensamiento universal, como característica necesaria de la crítica, defiende las diferencias de todo intento homogeneizador. En este sentido, es sensible con lo que sucede en diferentes territorios del planeta, pues entiende que la opresión acontece en todo el mundo y se manifiesta de múltiples maneras. Algunas vías para llegar a develarlas implican diálogo entre trabajos empíricos y el recurso a la filosofía, con la cual la geografía crítica puede tender puentes muy fructíferos, especialmente en el análisis de las contradicciones que entraña el modo de producción capitalista. Pensar alternativas a la depredación capitalista requiere, necesariamente, reflexionar sobre las especificidades de las contradicciones en cada territorio para que, desde ahí, se construyan estrategias de transformación social con repercusión global.

Antes que una aporía a esencialismos culturales, la perspectiva de la diferencia, como ha sido formulada por Henri Lefebvre en su Manifiesto diferencialista (1970), representa una apuesta por lo universal al reconocer que las diferencias existen entre los individuos del mundo entero. Pone el ejemplo de las mujeres y los niños, que difieren del hombre como categoría abstracta, y que también difieren entre los pueblos, pues

9 Respecto a la hegemonía que implica esto para la producción del conocimiento espacial, Berg sostiene que "Las geografías de otras personas y lugares son catalogadas como Otras - exóticas, transgresoras, extraordinarias y no representativas" (2004: 555).

Espiral 1(1): 051 - 058 | 051 
tienen necesidades propias que varían según los distintos momentos históricos. La diferencia no puede reducirse a representaciones banalizadas: originalidad, asociada al privilegio, al mito de los orígenes; diversidad, que no va más allá de una constatación; y distinción, "denominación elitista" y burguesa, que implica "vacío y vanidad", una toma de distancia respecto a un grupo. La diferencia tampoco es particularidad, pues la particularidad, en el sentido de individualidad, representa solamente el inicio. Hay un camino entre la particularidad y la diferencia y este camino no puede recorrerse con el pensamiento: requiere acciones, pruebas, luchas. El conflicto y la resistencia son necesarios para el reconocimiento de la diferencia, para su identificación. Si la particularidad es el inicio, el origen, la diferencia es el fin, el sentido. Entre ambas hay movimiento, conflicto, un rumbo colectivo manifiesto en acciones.

Lefebvre identifica que hay "combates titanescos" entre poderes homogeneizantes y poderes diferenciales, generalmente a la defensiva, latentes e irreductibles. Cuando estos llegan a la ofensiva, la victoria es el policentrismo. La victoria, entonces, implica la multiplicación de las formas de vida ${ }^{10}$, creación, descubrimiento, proliferación de estilos, posibilidad. Entonces, la diferencia implica lucha: es en el mundo de la cotidianeidad y en el esfuerzo por transformarla donde se cumple la diferencia. Ella es obra, concepto y actividad creativa, implica la defensa de la espontaneidad y del deseo. Es lo que realiza lo social como tal.

La diferencia está más vinculada a la palabra desarrollo, enriquecimiento social en un sentido cualitativo, antes que a la palabra crecimiento, regida por criterios cuantitativos impuestos por modelos de política económica. En esta línea, conviene atender el llamado de atención que hace Lefebvre respecto a los ideales productivistas del socialismo:

El socialismo, que tira de Marx su retórica y el lenguaje de sus decisiones, abandona su diferencia para fijarse los mismos objetivos que el capitalismo: producir, producir, siempre producir. (...) Desposeído de sí mismo, alienado, el socialismo ha perdido el aliento y "el alma", como se dice: ha perdido sentido. (Lefebvre, 1970: 26)

Esto hace pensar, por ejemplo, en las políticas públicas emprendidas por gobiernos municipales de izquierda, o con filiación de izquierda, que adoptan y ejecutan políticas neoliberales que apuntan a la acumulación, antes que a mejorar y expandir la calidad de vida. Lefebvre no habla de frenar el crecimiento, pero sí de limitarlo, de orientarlo de otra manera, de responder a las exigencias de cada sociedad, a las nuevas necesidades sociales (por ejemplo, a las necesidades urbanas) y contribuir, de una vez por todas, a limitar el tiempo de trabajo. Se trata de sustituir el desarrollo al crecimiento, la creatividad a la productividad, sin terminar con esta última. Por último, cuando hablamos de producción, no podemos ser reduccionistas y limitarnos a pensar en objetos, bienes y servicios. También es necesario engendrar nuevas relaciones sociales.

¿Qué tiene que ver todo esto con la geografía crítica? Ella implica ampliar e incluir, para desde ahí encontrar la mejor manera de entender lo nuevo de cada momento histórico, pero también, aquello que tiene de común y único en el mundo. El pensamiento diferencialista se pronuncia contra la indiferencia, contra lo repetitivo. En este sentido, busca la afirmación entendida como voluntad de diferir, de arriesgarse. Implica, de esta manera, la apropiación. "La propiedad fija y esteriliza. La dominación sobre la naturaleza produce y destruye. La apropiación desarrolla y transforma" (op.cit., p. 174). Existe una oposición entre lo complejo y lo simplificado, lo placentero y lo monótono. La diferencia se opone a la reducción, en tanto que esta aparece como instrumento ideológico y estratégico de la búsqueda de poder. También se opone a la integración y aboga, más bien, por el encuentro y el conflicto.

10 Sobre las formas de vida y prácticas sociales, Rahel Jaeggi dice que se encuentran materializadas en instituciones, al tiempo que se encuentran también materialmente en la arquitectura, cuerpos, herramientas, estructuras materiales en general que nos hacen actuar y son resultado de acciones. De esta manera, implantan límites y direccionan las acciones, implican una dinámica en sí mismas. "Nevertheless, they are something that human beings do and therefore could do otherwise" (Jaeggi, 2015: 18).

052 | Espiral 1(1): 052 - 058 
Pensar América Latina en clave diferencialista requiere entender que, en nuestras sociedades, la razón se encuentra limitada, pues el modo de producción dominante mermó nuestro vínculo con la naturaleza y entraña la destrucción de ecosistemas. Lefebvre habla de un mundo al revés en el que nos encontramos, lo que recuerda a la idea de Axel Honneth (2009) sobre las patologías que vive la razón humana en diferentes momentos históricos. Es en el mundo, donde la razón está enferma, donde

“(...) el dominio de la naturaleza por el conocimiento y la técnica destruyen la naturaleza, y esta destrucción alcanza la naturaleza en el ser humano (el deseo, la espontaneidad, el juego); de manera que hace falta vislumbrar la re-creación, la re-producción de la naturaleza en la más fuerte acepción de estos términos, de un salto hacia delante de la técnica orientada por el pensamiento" (Lefebvre, 1970: 144-145).

El mundo enfermo, de cabeza, es aquél donde se busca la destrucción de las diferencias, su asimilación a lo indiferente.

Si algo tienen en común las diferencias es su potencial emergencia en toda sociedad. Esta universalidad se manifiesta en las luchas emprendidas, por diversos grupos, contra poderes homogeneizantes. "Hay relación, generalmente escondida (no manifiesta) entre la lucha por diferir y todas las luchas, los dramas, los combates, todos los sufrimientos. Esta perspectiva no es solamente «inter-nacional»; ella es mundial" (op.cit., p. 51). La diferencia es también una cuestión de masas, nos recuerda Lefebvre.

Es esta idea la que vincula los combates de los Negros y de los estudiantes, de los intelectuales y de los pueblos (húngaro, checo, yugoslavo, vietnamita, etc.). De una manera convulsiva, por medio de giros, el ser mundial de lo que aún llamamos "hombre" y "humano" entra en el mundo de las diferencias. Y no entra en un país ya terminado, en un paisaje conocido, en una obra terminada. En cuanto concierne a lo diferencial, descubrimiento y creación van de la mano. (1970: 98)

Así, todos los pueblos participan de la universalidad dado que la cultura es algo universal, experimentada por todas las sociedades del planeta. “El Negro vale el Blanco. (...) La diversidad de culturas abre lugar a la unidad del espíritu humano (o de la «naturaleza humana»)" (op.cit., p. 182-183).

La misma defensa del carácter universal de las diferencias la encontramos en la obra de José María Arguedas. Recurrir a Arguedas ayuda a entender la multiespacialidad del pensamiento universal crítico, pues él supo distinguir lo propio de las luchas de los pueblos andinos del Perú y, a través de ellos, supo leer la miseria y la riqueza de la humanidad. La obra arguediana reconoce las injusticias en los territorios andinos y las entiende como resultado de un proceso motivado por intereses de una clase alta, blanca y terrateniente. Sumado al pensamiento multiescalar presente en sus obras, el gran legado arguediano reposa en haber situado las contradicciones vividas en los espacios indígenas y andinos como múltiples formas de opresión y resistencia experimentadas por las sociedades del mundo.

Como ha sugerido Alberto Escobar, a propósito de Todas Las Sangres, esta es una obra universal en tanto que las injusticias cometidas contra la población indígena se sitúan en un contexto internacional:

Todas las Sangres nos da la imagen del problema local, del problema humano, del problema regional, del problema regional frente a la capital, e incluye el Perú dentro del mecanismo internacional de los monopolios y los intereses internacionales, y coloca ahí esta situación del indio, y del mestizo, y del mundo limeño, y del mundo indígena, dentro de una perspectiva mundial (en Rochabrún, 2000: 36).

Los desarrollos desiguales dentro de la sociedad peruana son puestos de manifiesto, señalan los matices de un mismo proceso histórico. Esto recuerda a los motivos que impulsaron el surgimiento de la geografía crítica, la sublevación contra el imperialismo y contra los poderes hegemónigos a los que ataca Lefebvre en su Manifiesto Diferencialista. Guillermo Rochabrún sostiene que

“(...) los valores indígenas, como la fraternidad y la acción colectiva, son recogidos por él [Arguedas] no por ser indígenas, sino por su alcance universal. Otra cosa es que él los aprendiera de y en "los indios"; 
por eso puede haber personajes no indígenas, (...) quienes también asumen tales valores tras haberlos aprendido, al igual que el autor, a través de ellos" (op.cit., p. 99).

Arguedas sí veía en el mundo indígena las posibilidades de desarrollo endógeno, desde los colonos y los comuneros (op.cit., p. 108) ${ }^{11}$. En este sentido, nuevamente, el vínculo con Lefebvre se halla en la íntima creencia en la posibilidad de expansión de capacidades desde los propios individuos, restituir el placer, la dignidad, terminar con la indiferencia, para lo cual es necesario agruparse y luchar colectivamente. Así, encontramos la expresión de la diferencia en el conflicto. Una muestra de ello se ve en un capítulo de Los Ríos Profundos llamado "El Motín", donde se narra la revuelta de las chicheras ${ }^{12}$, quienes se organizan y desmantelan la complicidad existente entre los hacendados, la empresa Salinera y los representantes de la Iglesia en el pueblo de Patibamba, en Apurímac.

El capítulo cuenta cómo una multitud de mujeres mestizas, harta y rabiosa, reclama la justa repartición de la sal, vital para el consumo humano y también del ganado, que había sido acaparada por la empresa salinera para consumo exclusivo de las vacas de los hacendados. Se entabla un diálogo entre el Padre Linares, director de la escuela del pueblo de Patibamba, y Doña Felipa, la líder de la revuelta, quien cuestiona al párroco mientras este defiende a quienes guardan la sal para los hacendados. "¿Las vacas son antes que la gente, Padrecito Linares?", increpa Doña Felipa. De pronto, el Padre insulta a la líder, tras lo cual ella responde "iMaldita no, padrecito! ¡Maldición a los ladrones!", e inmediatamente, todo el grupo de mujeres enrumbó hacia el almacén de la Salinera. Se abrieron paso con el grito colectivo "iAvanzo, avanzo!", y algunos muchachos se unieron al movimiento, entre ellos Ernesto, personaje autobiográfico de Arguedas.

Una vez en el almacén encuentran muchos costales llenos de sal, lo que aviva la indignación. Doña Felipa llama al Padre Linares para que vea los costales acaparados por sus defendidos, pero el Padre no aparece. "Y comenzó el reparto. Presidió ella, desde lo alto del poyo. No hubo desorden. Con cuchillos, las chicheras encargadas abrían los sacos y llenaban las mantas de las mujeres" (Arguedas, 1986: 87). El reparto se hizo bajo el vigilante control de Doña Felipa, quien regulaba

(...) desde lo alto del poyo hasta los latidos del corazón de cada una de las enfurecidas y victoriosas cholas. Al menor intento de romper el silencio, ella miraba, y las propias mujeres se empujaban unas a otras, imponiéndose orden, buscando equilibrio. Del rostro ancho de la chichera, de su frente pequeña, de sus ojos apenas visibles, brotaba una fuerza reguladora que envolvía, que detenía y ahuyentaba el temor" (op.cit., p. 88).

El reparto tuvo en consideración a las indias pobres de Patibamba, para quienes Doña Felipa separó tres costales. A pesar de los insultos de los hacendados, el reparto de la sal en el pueblo fue una fiesta que, en medio de canciones, apagó los insultos. "Una inmensa alegría y el deseo de luchar, aunque fuera contra el mundo entero, nos hizo correr por las calles" (Id.Ibid.). Este evento no pasa sin estremecer visceralmente a Ernesto:

\footnotetext{
11 La comunidad es una institución sostenida en la apropiación de un territorio, que se basa en lazos de cohesión, identidad y visiones compartidas sobre qué hacer en dicho territorio. El gran hecho constitutivo de las comunidades son las reducciones de indios durante la Colonia, debido a que esta reconfiguración desterritorializa a poblaciones indígenas al tiempo que modifica profundamente las relaciones con su territorio y medio ambiente. Si durante la Colonia se reconoce una personería jurídica a la comunidad, durante la República las relaciones serán tensas con el Estado. Desde 1990, se vive un proceso de multiplicación y formalización de comunidades, de manera que la figura del comunero se transforma. El comunero no es necesariamente campesino, sino que puede ser un empresario, estudiante, etc. Lo curioso es que mucha gente del mundo campesino, para participar en ciertos territorios, se hace comunera. A diferencia del comunero, el colono es un actor vinculado a la territorialidad del Estado, pues contribuye a fortalecer su presencia en espacios considerados estratégicos o poco poblados. (Referencia elaborada gracias a una comunicación personal con el antropólogo Pável Aguilar Dueñas).

El término "colono" también se emplea para señalar a aquellas personas que llegaron después y se instalaron en el territorio indígena. Su presencia en el territorio resulta conflictiva, no solo por las diferentes formas de vida, sino por la disputa sobre la apropiación de la tierra. Sin embargo, es preciso notar que los colonos llegan a un territorio no solo por un efecto de atracción, sino también por un proceso de desplazamiento o expulsión.

12 En la novela, las chicheras son las mujeres que trabajan en el pueblo vendiendo chicha de jora, bebida de maíz fermentado.
}

054 | Espiral 1(1): 054 - 058 
Me eché bajo la sombra de la columna y de los árboles, y cerré los ojos. Se balanceaba el mundo. Mi corazón sangraba a torrentes. Una sangre dichosa que se derramaba libremente en aquel hermoso día en que la muerte, si llegaba, habría sido transfigurada, convertida en triunfal estrella" (op.cit., p.91).

La tristeza alcanza a Ernesto cuando se entera que los trabajadores de las haciendas obligaron a las indias de Patibamba a entregarles la sal que había sido repartida por las chicheras.

La participación de Ernesto en el movimiento involucra momentos de distanciamiento y reflexión en soledad. Esto recuerda la labor del geógrafo, o de quien busca comprender algún aspecto de la realidad y sabe que es necesario rumiar, digerir, buscar las palabras más adecuadas para nombrar aquello que nos hace sentido.

\begin{abstract}
Yo quedé fuera del círculo, mirándolos, como quien contempla pasar la creciente de esos ríos andinos de régimen imprevisible; tan secos, tan pedregosos, tan humildes y vacíos durante años, y en algún verano entoldado, al precipitarse las nubes, se hinchan de un agua salpicante y se hacen profundos; detienen al transeúnte, despiertan en su corazón y su mente meditaciones y temores desconocidos. (op.cit., p. 94)
\end{abstract}

La conjunción de compromiso y distanciamiento permite comprender el mundo, captarlo desde diferentes ángulos. De esta manera, lo que pasa en Patibamba no se expresa por el autor en clave folclórica, sino que es comprendido y expresado visceralmente, como una experiencia con alcance mayor, "(...) como algo muy serio que exige ser tomado en cuenta" (Gramsci, 2009: 278). En este sentido, Arguedas supo escuchar la realidad y buscó comprenderla, entre la rabia y el cariño. Como diría Gustavo Gutiérrez sobre el carácter universal de Arguedas, el escritor de Los Ríos Profundos entendía su obra y se entendía a sí mismo como un puente, un nexo entre mundos distintos (2014: 66). Arguedas aprendió sobre las múltiples injusticias que atraviesan a los pueblos andinos y asumió la expresión "todas las sangres" para hablar de los pueblos de todo el continente (op.cit., p. 113), del alcance universal de la opresión y de la rebeldía. La búsqueda del reconocimiento de los oprimidos alimentada por un ideal de justicia es parte del legado que nos deja su obra. La sensibilidad solar de Arguedas es el camino a prolongar como anhelada herencia para el quehacer de las ciencias humanas y sociales en el Perú, en América Latina y en el mundo.

\title{
3. Por una geografía crítica universal y diferencialista
}

La producción de conocimiento responde a la organización global de los circuitos de difusión de las investigaciones, a lógicas de competencia, acumulación y productivismo académico, así como a una superposición de juegos de poder dentro de las universidades, entre universidades y entre países. Existe confusión entre ambas cosas y el resultado es criticar el uso de marcos conceptuales no hechos en América Latina, cuando parece que en realidad lo que reclaman (no sin razón) algunos intelectuales es mayor participación y protagonismo en redes, en publicaciones y en debates globales. Muchas de estas críticas se hacen desde discursos postcoloniales, pero tal como se ha visto en este texto, no es preciso sacrificar el espíritu crítico universal para atender lo particular de la realidad local, tanto en el plano subjetivo como en el material. Atrincherarse en autores locales, autóctonos, no nos garantiza tener todos los elementos explicativos para comprender un problema y las lógicas que subyacen a la producción espacial. Tampoco garantiza posiciones intelectuales progresistas en defensa de la transformación y la justicia social.

Es indudable que las ideas, antes que circular por su valor intelectual, lo hacen según ciertas políticas macroescalares que definen qué conceptos resultan más atractivos y cómo han de difundirse, mientras que otros deben permanecer invisibilizados. Frente a esto, importa no perder de vista la geopolítica académica y contestar, con claridad, cómo se configura el poder en ella para evitar caer en victimizaciones facilistas que acusen sin más a los intelectuales del norte, por el hecho de ser del norte, de colonialismo académico hacia los intelectuales del sur. La producción espacial 
obedece a lógicas globales y locales de acumulación que, en esencia, se encuentran amalgamadas; de ahí la necesidad de que la investigación espacial -desde la geografía y las ciencias sociales- insista en el análisis situado y multiescalar. Se trata de hacer una geografía diferente, capaz de trabajar fuera de una lógica de competencia e individualismo, capaz de crear nuevos valores y revivir algunos dejados al olvido, como la solidaridad y la empatía.

Las diferencias de la realidad local podrán ser escuchadas y comprendidas críticamente por medio de una sensibilidad universal, solar, que considere la estructuración multiescalar de los procesos sociales. El pensamiento crítico sabe leer un hecho en sus manifestaciones locales y globales; solamente de este modo será posible pensar estrategias de autodeterminación y emancipación. En la década de 1980, Paul Claval sostenía que el movimiento radical en la geografía no llegaría a ser dominante mientras descanse sobre supuestos reduccionistas. Sin embargo, defendía la posibilidad de que represente “(...) el próximo paso en la evolución de la geografía de una concepción naturalista a una ciencia social, y, por tanto, a una disciplina humanística" (Claval, 1986: 281). Para el geógrafo francés, tal horizonte implicaba que la reflexión teórica ponga mayor atención a lo que hace diferente a las personas e instituciones.

Apostar por la diferencia implica abrazar un necesario componente subjetivo, sin caer en posturas metafísicas gaseosas, alejadas del análisis materialista. La diferencia es obra, concepto y actividad creativa, e implica la defensa de la espontaneidad y del deseo. Esto lo vemos presente en la revuelta de las chicheras, en Patibamba. Mujeres, indias y mestizas, identificadas con un objetivo común, toman las calles y la Salinera para acabar con aquello que resulta la manifestación más evidente de la injusticia, aunque acabar con la injusticia requiera de un movimiento mayor, multiescalar. Contestar un hecho injusto y decidir transformarlo, transforma el espacio opresor en algo otro, que a su vez transforma a la sociedad, y esto ha de ser evidenciado por la geografía crítica. La vulnerabilidad y el coraje de las chicheras representa la fuerza de los movimientos sociales progresistas alrededor del mundo, aquellos que transforman el miedo en alegría y fuerza, en orden y búsqueda de equilibrio, en deseo de luchar, en belleza. Si la dignidad humana es amenazada, quedan dos opciones, seguir las reglas del juego o transgredirlas. La geografía crítica jamás es neutral, ella toma posición por el reconocimiento de la dignidad de todos los pueblos, por su diferencia, expresada y reinventada continuamente.

\section{Bibliografía}

Albet, Abel; Benach, Núria; García, Luz M. y Santos, Xosé M. (2004). “Del postmodernismo a las nuevas geografías culturales, Mesa redonda del XVIII Congreso de la AGE. Bellaterra, 26 de septiembre de 2003", Treballs de la Societat Catalana de Geografia, 57, pp.141-158.

Arguedas, José María. (1984). Katatay, Lima: Editorial Horizonte.

Arguedas, José María. (1986). Los Ríos Profundos, Lima: Editorial Horizonte.

Benach, Núria. (2012). Richard Peet. Geografía contra el neoliberalismo, Barcelona: Icaria.

Berg, Lawrence. (2004). "Scaling knowledge: towards a critical geography of critical geographies", Geoforum, 35(5), pp.553-558.

Berg, Lawrence. (2010). “Critical Human Geography", en Warf, B. (dir.) The Encyclopedia of Geography, Londres: Sage Publishers, p.616-621.

Chibber, Vivek. (2013). Postcolonial Theory and the Specter of Capital, Londres: Verso.

Claval, Paul. (1986). “Conclusiones”, en Claval, Paul y Johnston, Ron (eds.), La Geografía Actual: Geógrafos y tendencias, Barcelona: Ariel.

Cox, Kevin. (2005). "From Marxist Geography to Critical Geography and Back Again", ponencia presentada en el Critical Geography Conference, Miami University.

056 | Espiral 1(1): 056 - 058 
Gintrac, Cécile. (2012). "Géographie critique, géographie radicale: comment nommer la géographie engagée?", Carnets de géographes, 4.

Gómez, Josefina; Muñoz, Julio y Ortega, Nicolás. (1988). El pensamiento geográfico. Estudio interpretativo y antología de textos (De Humboldt a las tendencias radicales), 2 da ed., Madrid: Alianza Editorial.

Gramsci, Antonio. (2009). Literatura y vida nacional, Buenos Aires: Las Cuarenta.

Gudynas, Eduardo. (2015). La necesidad de romper con un "colonialismo simpático", Rebelión, en: http://www.rebelion.org/noticia.php?id=203858

Gutiérrez, Gustavo. (2014). Entre las Calandrias. Un ensayo sobre José María Arguedas, Lima: Biblioteca Nacional del Perú.

Honneth, Axel. (2009). Patologías de la razón. Historia y actualidad de la teoría crítica. Buenos Aires: Katz.

Jaeggi, Rahel. (2015). Towards an Immanent Critique of Forms of Life, Raisons politiques, 57(1), pp.13-29.

Lefebvre, Henri. (1970). Le manifeste différentialiste, Paris: Gallimard.

Lefebvre, Henri. (2000). La production de l'espace, Paris: Anthropos.

Mitchell, Don. (2008). "Confessions of a Desk-Bound Radical." Antipode, 40 (3): pp. 448454.

Quijano, Aníbal. (1988). “Modernidad, identidad y utopía en América Latina”, en Calderón, Fernando (comp.), Imágenes Desconocidas. La modernidad en la encrucijada postmoderna, Buenos Aires: CLACSO.

Rochabrún, Guillermo. (2000). La Mesa Redonda sobre «Todas las Sangres» del 23 de junio de 1965, Lima: IEP-PUCP.

Silva-Santisteban, Rocío. (2017). Mujeres y conflictos ecoterritoriales. Impactos, estrategias, resistencias. Lima: DEMUS, AIETI, Flora Tristán, Coordinadora Nacional de Derechos Humanos

Urquijo, Pedro y Bocco, Gerardo. (2016). "Pensamiento geográfico en América Latina: retrospectiva y balances generales", Investigaciones Geográficas, Boletín del Instituto de Geografía UNAM, 90, p. 155-175.

Vilà Valentí, Joan. (1986). “La geografía en la Península Ibérica y en iberoamérica”, en Claval, Paul y Johnston, Ron (eds.), La Geografía Actual: Geógrafos y tendencias, Barcelona: Ariel, p.251-273.

Young, Iris M. (2000). La justicia y la política de la diferencia, Madrid: Ediciones Cátedra. 
058 | Espiral 1(1): 058 - 058 